Encontros Bibli: revista eletrônica de biblioteconomia e ciência da informação, v. 17, $n$. 34, p.17-30, maio./ago., 2012. ISSN 1518-2924. DOI:10.5007/1518-2924.2012v17n34p17

\title{
CONSTRUÇÃO DE LINGUAGENS DOCUMENTÁRIAS EM SISTEMAS DE RECUPERAÇÃO DA INFORMAÇÃO: A IMPORTÂNCIA DA GARANTIA DO USUÁRIO
}

\author{
Dalgiza Andrade Oliveira ${ }^{\mathrm{i}}$ \\ Ronaldo Ferreira de Araujo ii
}

\begin{abstract}
Resumo: $\mathrm{O}$ artigo pretende discutir a importância da garantia do usuário no processo de planejamento e elaboração de linguagens documentárias. Assim, o trabalho de cotejamento foi realizado por meio de revisão de literatura de estudos de autores que abordam tal temática, dentro do escopo do processo classificatório, encontrado na Biblioteconomia e na Ciência da Informação. O artigo, embora concentre sua atenção na garantia do usuário, conceitua sinteticamente a garantia literária, a garantia estrutural e a garantia cultural. Discorre-se conceitualmente acerca dos Sistemas de Recuperação de Informação e dos Sistemas de Informação, das linguagens documentárias e das representações documentárias utilizadas no processo de organização da informação. Dentre as linguagens documentárias, com ênfase na representação da informação, é destacado, especificamente, o tesauro, enfocando as suas principais características no que se refere à validação de termos. Aborda os mecanismos de indexação e descrição dos documentos. Pode-se inferir que o processo de desenvolvimento dos Sistemas de Recuperação da Informação depreende, notadamente, do avanço da ciência e da tecnologia a contar de meados do século passado. No que diz respeito à construção de uma linguagem documentária, a exemplo do tesauro, conclui-se que a garantia do usuário representa um fator relevante posto que configura como a legitimação de termos que se utiliza em suas demandas de pesquisa e informação.
\end{abstract}

Palavras-chave: Garantia do usuário. Organização do conhecimento. Tesauros. Representações documentárias. Indexação.

\section{DOCUMENTARY CONSTRUCTION OF LANGUAGES IN INFORMATION RETRIEVAL SYSTEMS: THE IMPORTANCE OF USER'S WARRANTY}

\begin{abstract}
The article intends to discuss the importance of ensuring the user warranty in the process of planning and preparation of documentary languages. Thus, the work of collation was done through literature review of studies of authors who address this issue within the scope of the classification process, found in the Librarianship and Information Science. The article, while focusing its attention on ensuring the user warranty, defines synthetically the literary, structural, and cultural warranties. It talks conceptually about the Systems Information Retrieval and Information Systems, the documentary language and documentary representations used in the process of organizing information. With emphasis on the representation of information, among the indexing languages, the thesaurus, specifically, is highlighted, focusing on its main characteristics in terms of validation. The article also discusses the mechanisms of indexing and description of documents. It can be inferred that the development process of information retrieval systems emerges, in particular, from the advancement of science and technology after the middle of the last century. Regarding the construction of a documentary language, such as the thesaurus, it is concluded that user warranty is a relevant factor since it sets as the legitimation of terms that are used in their demands for research and information.
\end{abstract}

Keywords: User warranty. Knowledge organization. Thesauri. Documentary representations. Indexing.

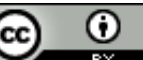

Esta obra está licenciada sob uma Licença Creative Commons

\footnotetext{
${ }^{\mathrm{i}}$ Universidade Federal de Alagoas. dalandrade@yahoo.com.br.

${ }^{i i}$ Universidade Federal de Alagoas. ronaldfa@gmail.com.

Recebido em: 24/03/2012; aceito para publicação em: 06/07/2012.
} 


\section{INTRODUÇÃO}

Os Sistemas de Recuperação da Informação tiveram seu crescimento associado ao grande aumento de documentos ocasionado, notadamente, a partir da Segunda Guerra Mundial, o que comumente os autores do campo da Ciência da Informação denominam boom bibliográfico (FONSECA, 1974; COSTA, ORRICO, 2009; MIRANDA, 2002; OLIVEIRA, 2005).

No crescente desenvolvimento desses Sistemas, as linguagens documentárias têm se configurado como recursos indispensáveis. As linguagens documentárias, mediante seus produtos, podem possibilitar a comunicação sistema-usuário, tendo em vista que funcionam como instrumentos auxiliares no processo da representação da informação.

Os vocabulários controlados, como parte das linguagens documentárias, se apresentam como instrumentos essenciais na atividade de indexar e recuperar documentos. No processo de construção de um vocabulário controlado, especificamente um tesauro, alguns critérios devem ser considerados, dentre os quais destaca-se a garantia do usuário.

Os estudos desenvolvidos por autores como Moreira e Moura (2006) e Barité (2007) na área da Ciência da Informação e Biblioteconomia, que abrangem as linguagens documentárias, têm apontado, na maioria das vezes, que no levantamento de termos para a montagem de um tesauro, a garantia do usuário funciona como um elemento essencial.

Nessa perspectiva, este artigo pretende discutir a importância da garantia do usuário no processo de planejamento e elaboração de linguagens documentárias. Para tanto, discorrese sinteticamente acerca dos Sistemas de Recuperação de Informação, bem como das linguagens utilizadas no processo de representação da informação, destacando, especificamente, o tesauro. Vale ressaltar que, além da garantia do usuário, outros critérios devem ser considerados no planejamento e na elaboração das linguagens documentárias, a saber: a garantia literária, a garantia estrutural e a garantia cultural.

Nessa direção, faz-se necessário caracterizar primeiramente a garantia literária, que na sua concepção original para Barité e colaboradores (2010, p. 124) "se sustenta na ideia nuclear de que a literatura de um domínio deve ser a fonte para extração e validação da terminologia a ser incorporada em um sistema de classificação, ou em qualquer outro sistema de organização do conhecimento". Vista sob essa perspectiva, prosseguem os autores, a documentação tem o papel de catalisar o processo em que se encontra 
documentos e recursos de informação de qualquer natureza, com vista a sua recuperação em face de demandas concretas de usuários com distintos níveis de instrução e com variados interesses e necessidades de informação. (BARITÉ et al, 2010, p. 124)

Denominam-se garantia estrutural, por sua vez, de acordo com Moura e Moreira (2006), termos cuja colocação encontra justificativa na estrutura do tesauro.

Já a respeito da garantia cultural, de acordo com Begthol (2002 apud Pinho, 2010), compreende-se que "qualquer tipo de sistema de organização e/ou representação do conhecimento pode ser apropriado e útil para os indivíduos em alguma cultura, somente se for baseado nas suposições, valores e predisposições daquela mesma cultura".

Com base nas abordagens de autores que pesquisam essas temáticas, sobretudo àquelas que se voltam para os estudos dedicados à garantia do usuário (considerando seu alto grau de escassez) é que se apresenta esta revisão da literatura. Há de se considerar e destacar, também, que os temas tratados nesse artigo inscrevem-se na área de abrangência do processo classificatório.

\section{SISTEMAS DE RECUPERAÇÃO DA INFORMAÇÃO}

Os Sistemas de Informação têm suas origens nas Bibliotecas de Terracota na Babilônia, Pergaminho em Pérgamo, e de Papiro em Alexandria. No decorrer de seu desenvolvimento, esses sistemas passaram por enormes mudanças até a atualidade do mundo virtual. Os Sistemas de Informação são os que buscam a realização de processos de comunicação, enquanto que os Sistemas de Recuperação da Informação podem ser entendidos como "tipos de sistemas de comunicação que, entre outras funções, visam dar acesso às informações neles registradas”. (ARAÚJO, 1995)

Dentre outros fatores, Lopes (2002, p. 60) acentua que "esses sistemas possibilitam o planejamento de estratégias de busca com maior nível de complexidade envolvendo vários conceitos na mesma estratégia". Além disso, esses sistemas permitem a utilização de busca de palavras apenas dos títulos e resumos dos documentos, isto é, termos da linguagem natural; buscam os termos específicos de linguagens controladas, nos campos de descritor; buscam por autores; por ano de publicação; por títulos de periódicos; por classificação; permitem, também, a busca de conceitos compostos ou simples e a possibilidade de truncagem de raízes 
de palavras e de substituição de caracteres no meio dos termos, dentre outros recursos de recuperação. (LOPES, 2002, p. 60)

Os Sistemas de Recuperação da Informação organizam e viabilizam o acesso aos itens de informação a partir do desempenho das tarefas de representação das informações contidas nos documentos. Tal processo se materializa, geralmente, por meio da indexação e descrição desses documentos; armazenamento e gestão física e/ou lógica destes, bem como de suas representações e, também, pela recuperação das informações representadas e dos documentos armazenados com a finalidade de atender às necessidades dos usuários. (SOUZA, 2006)

Sendo assim, as linguagens documentárias ocupam um papel de destaque na operacionalização e no funcionamento de um Sistema de Recuperação da Informação, tendo em vista que a partir de seus produtos busca-se melhorar a comunicação ou os instrumentos de comunicação. (DODEBEI, 2002)

\section{LINGUAGENS DOCUMENTÁRIAS}

As linguagens documentárias, em consonância com a escala complexa das representações sociais, são entendidas como metarrepresentações ou representações documentárias e operam no quadro dessas representações como linguagens de comunicação entre a informação documentária e o usuário que a demanda. (DODEBEI, 2002)

A Ciência da Informação, para Lara (2001), "quando constroi linguagens documentárias, tem como objetivo assegurar a organização e a transferência da informação". Considerando que a informação configura-se como uma construção, a linguagem documentária tem como um de seus propósitos apresentar-se como uma forma de organização da informação. Nesse aspecto, a linguagem documentária articula temas, subtemas e termos orientados a fim de dar conta dos conjuntos documentários, bem como da transferência da informação para determinados usuários, considerando objetivos específicos.

Autoras como Pereira e Bufrem (2005), ao discutirem a representação documentária, entendem que esta se apresenta como o resultado de uma prática iniciada com a análise do texto que identifica conteúdos pertinentes em consonância com os propósitos e características da unidade ou sistema a que serve. As mesmas autoras pontuam que a representação de conteúdos informacionais, em plano real, fundamenta-se nas operações de análise e síntese. Esse processo se materializa quando são criados códigos de classificação bibliográficos, 
tesauros, índices de sistemas de informação e resumos/abstracts, produtos documentários que podem ser considerados "modelos" de representação das mais diversas realidades. (PEREIRA; BUFREM, 2005)

No quadro abaixo é possível visualizar, a partir da ilustração de Dodebei (2002), a representação documentária por meio dos objetos, processos, produtos, instrumentos, usos e campos teórico-metodológicos:

Quadro 1 - Representação Documentária
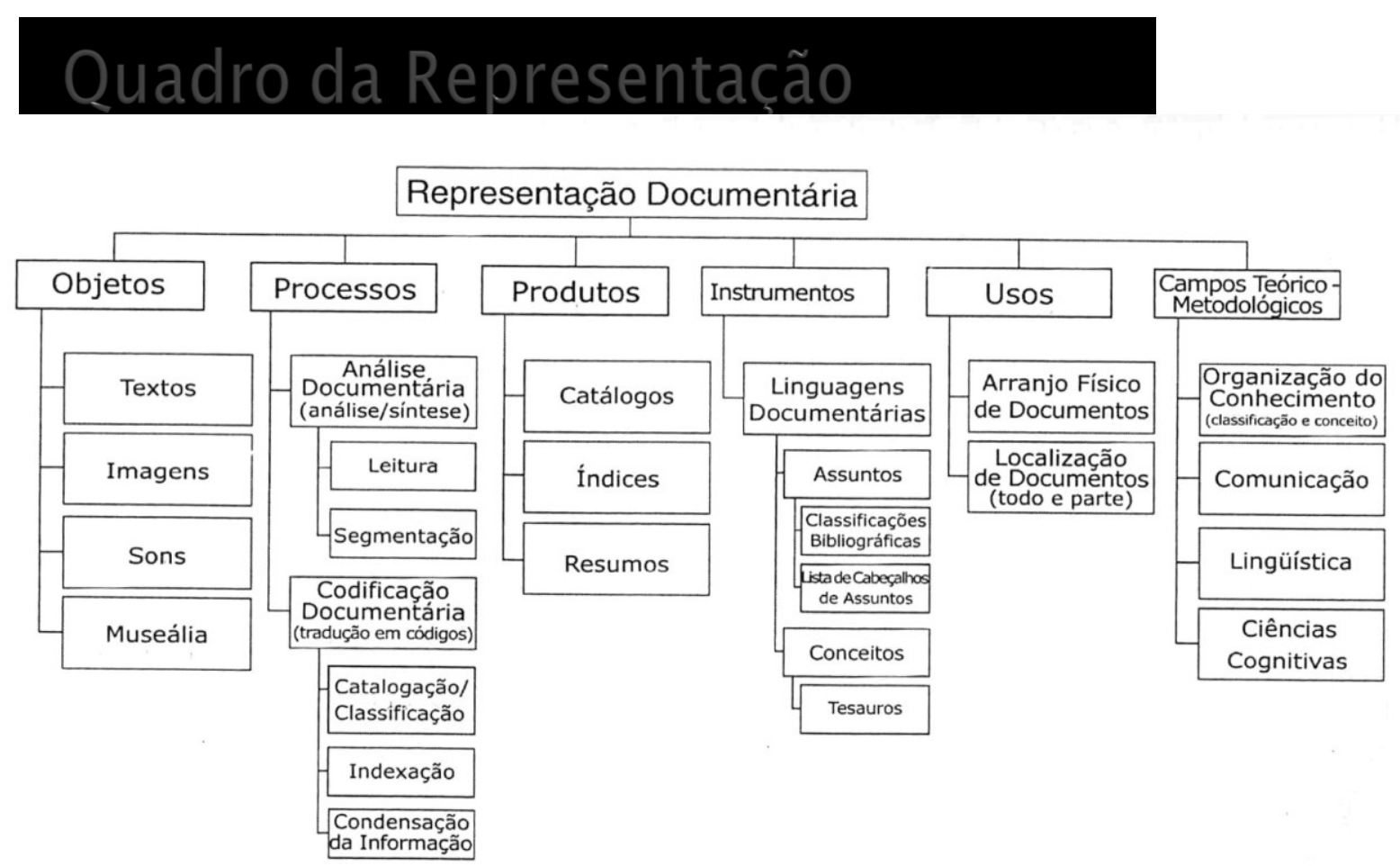

Fonte: DODEBEI (2002, p. 43)

\subsection{Tesauros}

No que concerne aos produtos resultantes do desenvolvimento das linguagens documentárias, o tesauro aparece como um importante instrumento de vocabulário 
controlado $^{3}$, uma vez que trabalha com a organização do campo terminológico específico de uma dada área do conhecimento.

Na sua abordagem sobre as linguagens de indexação, Foskett (1973, p. 41) afirma que "uma lista de termos em que se indica a sua classificação de acordo com as ideias que eles representam é chamada de thesaurus". Esse tipo de lista só pode ser compilado por intermédio da indexação de conceitos, podendo constituir-se na primeira etapa do desenvolvimento de uma linguagem de indexação completamente artificial. (FOSKETT, 1973)

De acordo com Moreira e Moura (2006), "um tesauro é uma linguagem de documentação com

a característica específica de possuir relações entre os termos que o compõe". Dando continuidade à caracterização dos tesauros, os autores explicam que o termo linguagem de documentação "compreende, genericamente, os sistemas de classificação bibliográfica, as listas de cabeçalho de assunto e os tesauros”. (MOREIRA; MOURA, 2006)

Os tesauros tiveram seu uso acentuado a partir do desenvolvimento da Ciência e da Tecnologia. A crescente necessidade de obterem-se instrumentos para facilitar a recuperação da informação de maneira mais específica parece ter sido fator determinante na ampliação do uso dos tesauros. À medida que o conhecimento foi se fragmentando e atingindo um grau maior de especialização e especificidade, os tesauros passaram a ser adotados também em outros campos do saber. Vale ressaltar que o advento das chamadas novas tecnologias de informação e comunicação têm propagado ainda mais a adoção de tesauros.

A Ciência da Informação passou a utilizar o termo tesauro a partir da década de 1940; sua aplicabilidade se deu, sobretudo, no processo de recuperação da informação funcionando como um instrumento capaz de transportar conceitos e suas relações mútuas, tal como expressos na linguagem de documentos, em língua regular, com controle de sinônimos e estruturas sintáticas simplificadas. (DODEBEI, 2002)

$\mathrm{Na}$ relação intrínseca dos tesauros com a Ciência da Informação, o estudo destes envolve diversos campos do conhecimento, pois o tema é, em si, multidisciplinar. Como área de estudo da Ciência da Informação, multidisciplinar por natureza e interdisciplinar na vocação, o tesauro herda dessa ciência essas propriedades. Nesse sentido, liga-se à Ciência da

\footnotetext{
${ }^{3}$ Os Vocabulários Controlados caracterizam-se por uma lista de termos autorizados e os principais modelos são os esquemas de classificação bibliográfica, listas de cabeçalhos de assuntos e tesauros. (LANCASTER, 2004)
} 
Informação por sua origem e utilização imediata nos processos de indexação e recuperação de informação.

No que diz respeito, ainda, ao estudo dos tesauros, é relevante destacar que este também vincula-se às contribuições da Terminologia, da Linguística, da Filosofia, da Lógica, da Tradução, da Análise Sistêmica, da Normalização, dos Sistemas de Classificação, entre outros.

Dentre as principais funções de um tesauro, destacam-se o controle de sinônimos e quase sinônimos e a distinção de homógrafos. O tesauro possibilita, ainda, a facilidade na condução da busca por intermédio dos termos relacionados e das referências cruzadas de maneira a permitir uma consistência melhor da indexação e do transporte da linguagem de busca para a linguagem de indexação. Dessa maneira, o tesauro pode reduzir o tempo e aumentar a eficiência nas atividades de indexação e recuperação da informação. (LANCASTER, 1972 apud DODEBEI, 2002)

Na compreensão de Moreira e Moura (2006), “os tesauros constituem uma ferramenta de indexação já consolidada nas atividades de organização da informação empregada por muitos que exercem esta atividade". Para Rowley (1994), o tesauro apresenta-se como "uma ferramenta útil para restringir ou ampliar os assuntos das buscas". Dessa forma, a utilização corrente dos tesauros tem servido as mais diversas disciplinas do saber, possibilitando agilidade nos procedimentos que envolvem a recuperação da informação.

\subsection{Tesauros e Garantia do Usuário}

No processo de construção de um tesauro, alguns aspectos devem ser considerados a fim de obterem-se resultados que possam legitimá-lo perante o campo específico para o qual esteja sendo desenvolvido. Dentre eles, destaca-se, além da garantia literária ${ }^{4}$ e da garantia estrutural $^{5}$, a garantia do usuário, tendo em vista que este deverá ser o maior beneficiário desta ferramenta de recuperação da informação.

Ao analisar a importância da temática da garantia do usuário, encontram-se, na literatura, termos similares, como "garantia de uso", ou "endosso do usuário". Na construção das linguagens documentárias, observa-se que esses termos vinculam-se fortemente às linguagens de indexação que se apresentam como instrumentos indispensáveis à recuperação

\footnotetext{
${ }^{4}$ Conceito introduzido por Hulme (1950) em sua obra Principles of Book Classification.

5 Segundo Moreira e Moura (2006, página $i_{i}$ ), a garantia estrutural pode ser entendida como "termos cuja colocação encontra justificativa na estrutura do tesauro".
} 
da informação. Diante disso, pode-se conceber que indexação, de acordo Naves (2004), no campo do tratamento da informação,

apresenta dois sentidos: um mais amplo, quando se refere à atividade de criar índices, seja de autor, de título, de assunto, tanto de publicações (livros, periódicos), quanto de catálogos ou de banco de dados, em bibliotecas ou centros de informação. O outro sentido, mais restrito, refere-se à indexação, classificação ou catalogação de assuntos das informações contidas em documentos. (NAVES, 2004)

A indexação pode ser ainda o processo de compreensão da essência do conteúdo de um documento e representação deste num modo de expressão em linguagem de indexação. Outros autores atribuem a esse processo o nome de análise documentária. ${ }^{6}$ A definição de análise documentária parte da premissa de que esta se apresenta como um conjunto de métodos efetuados com a finalidade de expressar o conteúdo de documentos, de forma a possibilitar a recuperação da informação. O processo de transferência de um texto original para um tipo de representação

é sem dúvida uma operação semântica, mesmo que ela não obedeça, na maioria das vezes, a nenhuma espécie de regra precisa, e que cada organismo de documentação, e mesmo cada analista, se limite a buscar, neste caso, certa regularidade interna, fundada muito mais na experiência ou no hábito, do que em algum tipo de procedimento explícito. (GARDIN, 1974, p. 81-82)

Em consonância com Moreira e Moura (2006), “comumente, a garantia do usuário é sempre considerada na criação de uma linguagem de documentação e é muito raro existirem tentativas contrárias a esse princípio pelos especialistas nessas linguagens”. De acordo com os autores, há muitos estudos nessa área, incluindo trabalhos que pesquisam em registros de transações feitas em bases de dados dispostas em tecnologia de bancos de dados. Nesses instrumentos, há a possibilidade de retomar a consulta de um usuário e tentar medir a adequação do vocabulário por ele utilizado nas rotinas de busca com os vocabulários normalizados de linguagens de documentação. Dessa forma, esses estudos têm demonstrado que, no nível léxico, a colisão nem sempre se dá em nível significativo. Todavia, no nível conceitual, em que os autores desses trabalhos contabilizam os sinônimos e as relações genéricas, observa-se que este é consideravelmente alto. Sendo assim,

tal fato fez com que Svenonius (2000) definisse que encontrar a linha de uso comum entre os termos nem sempre é o alvo principal para identificar os conceitos nos quais um usuário está interessado, mas é fundamental para dar nome a estes conceitos.

\footnotetext{
${ }^{6}$ Conf. SMIT, Johanna W. (Coord). Análise documentária: a análise da síntese. Brasília: IBICT, 1987.
} 
Além de que, são muitos usuários diferentes e com usos distintos, e para traçar um vocabulário normalizado é necessário incluir todos os nomes pelos quais um conceito é conhecido. (MOREIRA; MOURA, 2006)

Para Barité (2007, tradução nossa) ${ }^{7}$, a garantia do usuário "se sustenta na ideia de que o processo de seleção de termos deve estar associado às formulações de busca que os usuários realizam ante um sistema de informação, e na forma em que elas se manifestam". Dentre os instrumentos das linguagens documentárias e nos aspectos em que se percebe a importância da garantia do usuário, os tesauros, em seu processo de consolidação, lançam mão desse recurso.

Do ponto de vista histórico, Moreira e Moura (2006) acentuam que "também a garantia de uso já era observada ao longo da história de consolidação dos tesauros”. Esses mesmos autores, ao mencionarem o estudo de Gilchrist, realizado em 1971, indicam que esse autor trabalhou a garantia de uso em consonância com o contexto de sua época, tendo-a como uma força paralela de pensamento na medida em que o leitor, como usuário e frequente criador de literatura, deveria ser empregado como uma fonte para se conhecer a linguagem mais apropriada para a indexação. Gilchrist complementa, ainda, que "os modelos que levam em conta o usuário estão diretamente relacionados com o potencial da necessidade de informação do usuário e com a linguagem por ele utilizada: uma linguagem 'espontânea' com a qual expressa seu pedido de informação" (GILCHRIST, 1971 apud MOREIRA; MOURA, 2006).

No processo de confecção das linguagens documentárias, outros autores consideram, também, que os indexadores devem trabalhar com base na garantia da qualidade da recuperação da informação pelos usuários (BOCCATO; PRATI; TRINDADE, 1996; OLIVEIRA, 2004; SAMPAIO et al, 2004).

Discorrendo sobre os princípios norteadores da indexação, Lancaster (2004, p. 9) manifesta sua preocupação com os usuários quando afirma que "uma indexação de assuntos eficiente implica que se tome uma decisão não somente quanto ao que é tratado num documento, mas também por que ele se reveste de provável interesse para determinado grupo de usuários". Afirma esse autor, ainda, que "quanto mais especializada a clientela de um centro de informação, maior é a probabilidade de que a indexação possa e deva ser feita sob medida, ajustando-se com precisão aos interesses do grupo”. (LANCASTER, 2004, p. 10)

\footnotetext{
${ }^{7}$ No original: "se sostiene em la idea de que el proceso de selección de términos debe estar asociado a las formulaciones de búsqueda que los usuarios realizan ante un sistema de información, y a la manera en que ellas se manifiestan" (BARITÉ, 2007).
} 
Para Lancaster (1987 apud MORAES; CRISTIANINI, 2008), o processo de coleta de termos com base no usuário da informação é, reconhecidamente, uma das maneiras de compilação e validação da terminologia para a elaboração de linguagens documentárias, e é denominado "garantia do uso comum, endosso do usuário ou consenso". Nessa direção, a preocupação de Lancaster (2004) com o usuário é corroborada por outros autores, tais como Fidel (1994), ao utilizar a expressão "indexação centrada no usuário", uma vez que define que o princípio da indexação tem que ter sua base nas solicitações que são esperadas por um dado grupo. HjØrland (2001), por sua vez, entende que a indexação deve ser formatada ajustandose à determinada clientela. Nessa linha, Bates (1998) enfatiza que, como desafio, o indexador deve tentar antecipar quais expressões os indivíduos utilizariam quando se depararem com necessidade de informação dos mais variados tipos, ou ainda, que termos buscariam nas situações em que o registro de que dispõem não atendesse às suas demandas. (LANCASTER, 2004)

No que se refere, ainda, à indexação voltada para participação do usuário, Lancaster (2004, p. 12) alerta que "é preciso que os indexadores saibam muito mais do que os princípios da indexação. Devem, em especial, estar inteiramente a par dos interesses da comunidade atendida e das necessidades de informação de seus membros".

Ferreira (1996), em seu estudo sobre os novos paradigmas da informação e novas percepções do usuário, polemiza quando infere que "por outro lado, ainda, a abordagem tradicional não tem examinado os fatores que geram o encontro do usuário com os sistemas de informação ou as consequências de tal confronto". Dessa forma, a autora prossegue criticando a abordagem tradicional, acentuando que esta "limita-se à tarefa de localizar fontes de informação, não levando em consideração as tarefas de interpretação, formulação e aprendizagem envolvidas no processo de busca de informação".

A preocupação com a percepção do usuário é encontrada também em Barité (2007, tradução nossa), quando esse autor menciona que "a tendência mais recente aponta que os tesauros e outras linguagens documentárias podem ajustar sua estrutura de conhecimento às estruturas cognitivas dos usuários, à sua linguagem e à sua maneira de buscar informação"»

Embora reconheça-se a importância da garantia do usuário no processo de construção de vocabulários controlados, sobretudo de tesauros, são poucos os casos empíricos ou mesmo

\footnotetext{
${ }^{8}$ No original: "la tendencia más reciente apunta a que los tesauros y otros lenguajes documentales pueden ajustar su estrutura de conocimiento a las estructuras cognitivas de los usuários, a su lenguje y a su manera de buscar información" (BARITÉ, 2007). 
relatos de experiências que retratam como os profissionais e pesquisadores da Biblioteconomia e Ciência da Informação têm inserido o usuário nesse processo.

No relato de experiência de Corrêa e Thomes (2008) sobre a construção do Tesauro do Centro de Informação e Documentação do Serviço de Apoio a Pequena e Média Empresa do Espírito Santo (CID-SEBRAE/ES), as autoras destacam que a garantia do usuário esteve presente na "definição dos termos candidatos e dos termos não candidatos" e na estruturação semântica do instrumento de indexação "em reuniões com técnicos especialistas de cada área coberta pelo tesauro" (CORREAA; THOMES, 2008).

Vale destacar, também, que na experiência do Tesauro da Cadeia Alimentícia, o processo da garantia do usuário foi possível na determinação do termo preferido e seus sinônimos, na análise e validação do instrumento por meio da "participação de indexadores de diferentes instituições nacionais e estrangeiras". (INFOTHES, 2008)

\section{CONSIDERAÇÕES FINAIS}

A partir das discussões desenvolvidas, pode-se inferir que o processo de desenvolvimento dos Sistemas de Recuperação da Informação provém, notadamente, do avanço da ciência e da tecnologia a contar de meados do século XX.

A Ciência da Informação necessita, obrigatoriamente, de estudos mais elucidativos sobre os processos que envolvem os Sistemas de Recuperação da Informação, tendo em vista que muitos pesquisadores que reivindicam seu status advogam que suas origens decorrem da necessidade de atender a explosão informacional a partir da Segunda Grande Guerra.

Nesse percurso, as linguagens documentárias têm contribuído no atendimento à busca pela informação mediante seus recursos, como os vocabulários controlados, utilizados para possibilitar maior eficácia na recuperação da informação.

No que concerne aos tesauros, em particular, compreende-se que são instrumentos imprescindíveis à sistematização e disseminação do conhecimento humano, uma vez que a fragmentação das disciplinas assim o exigem.

No que diz respeito à construção de uma linguagem documentária, a exemplo do tesauro, a garantia do usuário torna-se um fator relevante, visto que configura como a legitimação de termos utilizados em demandas de pesquisa e informação. 


\section{REFERÊNCIAS}

ARAÚJO, V. M. R. H. de. Sistemas de Informação: nova abordagem teórico-conceitual. Ciência da Informação, Brasília, v. 24, n. 1, 1995. Disponível em: $<$ http://dici.ibict.br/archive/00000141/01/Ci\%5B1\%5D.Inf-2004-577.pdf .>. Acesso em: 7 out. 2007.

BARITÉ, M. et al. Garantia literária: elementos para uma revisão crítica após um século. TransInformação, Campinas, v. 22, n. 2. p. 123-138, maio/ago., 2010. Disponível em: $<\mathrm{http}$ ://revistas.puc-campinas.edu.br/transinfo/viewissue.php?id=25>. Acesso em: $12 \mathrm{fev}$. 2011.

La garantía literaria: vigencia y proyección teórico-metodológica. In: ENCONTRO NACIONAL DE PESQUISA EM CIÊNCIA DA INFORMAÇÃO, VIII, 2007, Salvador. Anais... Salvador: Associação Nacional de Pesquisa e Pós-Graduação em Ciência da Informação, 2007.

BOCCATO, V. R. C.; PRATI, S. C.; TRINDADE, V. C. S. Estudo de compatibilização de linguagens documentárias na área odontológica para o banco de dados bibliográficos da USP - DEDALUS. Ciência da Informação, Brasília, v. 25, n. 2, 1996. Disponível em: $<$ http://www.ibict.br/cienciadainformacao/viewissue.php?id=31 $>$. Acesso em: 12 out. 2007.

CORRÊA, L. H. M.; THOMES, J. L. Tesauro de CDI-SEBRAE/ES (Online). 2008. Disponível em: <http://www.comunidade.sebrae.com.br/biblioteca/Artigos/23093.aspx>. Acesso em: 13 Set 2009.

COSTA, R. S.; ORRICO, E. G. D. A construção de sentido na informação das histórias em quadrinhos. DataGramaZero: revista de Ciência da Informação, v. 10, n. 2, abr. 2009. Disponível em:< http://www.dgz.org.br/abr09/Art_01.htm>. Acesso em: 15 fev. 2010.

DODEBEI, V. L. D. Tesauro: linguagem de representação da memória documentária. Niterói: Intertexto; Rio de Janeiro: Interciência, 2002.

FERREIRA, S. M. S. P. Novos paradigmas da informação e novas percepções do usuário. Ciência da Informação, Brasília, v. 25, n. 2, 1996. Disponível em: < http://revista.ibict.br/ciinf/index.php/ciinf/article/view/440/398 >. Acesso em: 12 out. 2007.

FONSECA, E. N. da. Ler ou não ler todos os livros. Revista de Biblioteconomia, Brasília, jan./ jun., 1974.

FOSKETT, A. C. A abordagem temática da informação. São Paulo: Polígono; Brasília: Ed. Universidade de Brasília, 1973.

GARDIN, J.-C. Les analyses de discours. Neuchâtel: Delachaux et Niestlé, 1974. p. 81-82

HULME, E. W. On the definition of class headings, and the natural limit to the extension of book classification. In: 1950. cap. 3, p. 444-449. . Principles of book classification. Library Association Record, 
INFOTHES. Tesauro da Cadeia Alimentícia, 2008. Disponível em: $<$ http://www.infothes.inf.br/tesauros.htm>. Acesso em: 22 set. 2008.

LANCASTER, F. W. Indexação e resumos: teoria e prática. 2. ed. Brasília: Briquet de Lemos/Livros, 2004.

LARA, M. L. G. de. O unicórnio (o rinoceronte, o ornitorrinco...), a análise documentária e a linguagem documentária. Data grama zero: revista de Ciência da Informação. v. 2, n. 6, dez. 2001. Disponível em: <http://www.dgz.org.br/dez01/Art_03.htm>. Acesso em: 15 set. 2007.

LOPES, I. L. Estratégia de busca na recuperação da informação: revisão da literatura. Ciência da Informação, Brasília, v. 31, n. 2, mai./ago. 2002. Disponível em: $<$ http://revista.ibict.br/index.php/ciinf/article/view/158>. Acesso em: 15 set. 2007.

MIRANDA, A. A Ciência da Informação e a teoria do conhecimento objetivo: um relacionamento necessário. In: AQUINO, Mírian de Albuquerque. O Campo da Ciência da Informação: gênese, conexões e especificidade. João Pessoa: Editora Universitária/ UFPB, 2002. p. 9-24. Disponível em: $<$ http://www.antoniomiranda.com.br/ciencia_informacao/conhe_objetivo.html $>$. Acesso em: 10 fev. 2011.

MORAES, J. de S.; CRISTIANINI, G. M. S. Terminologia de Matemática: revisão da área para o vocabulário controlado da USP. In: SEMINÁRIO NACIONAL DE BIBLIOTECAS UNIVERSITÁRIAS, XV, 2008, São Paulo. Anais...São Paulo: CRUESP, 2008. Disponível em: <http://www.sbu.unicamp.br/snbu2008/anais/site/pdfs/3271.pdf >. Acesso em: 18 fev. 2011.

MOREIRA, M. P.; MOURA, M. A.. Construindo tesauros a partir de tesauros existentes: a experiência do TCI - Tesauro em Ciência da Informação. DataGramaZero: Revista em Ciência da Informação, v. 7, n. 4, ago. 2006. Disponível em: $<$ http://www.dgz.org.br/ago06/F_I_art.htm .> Acesso em: 25 set. 2007.

OLIVEIRA, M. de. (Coord.). Ciência da Informação e Biblioteconomia: novos conteúdos e espaços de atuação. Belo Horizonte: Ed. da UFMG, 2005.

OLIVEIRA, V. de F. F. de. O pesquisador de palavras e o pesquisador de imagens: reflexões sobre a organização de bancos de dados e imagens em artes. ETD-Educação Temática Digital, v. 6, n. 1, dez. 2004. Disponível em: <http://dici.ibict.br/archive/00000231/>. Acesso em: 10 out. 2007.

NAVES, M. M. L. Curso de indexação: princípios e técnicas de indexação, com vistas à recuperação da informação. Disponível em: $<$ http://www.finaltec.com.br/oicd/uploads/principios_tecnicas_de_indexacao.doc $>$. Acesso em: 6 out. 2007.

PINHO, F. A. Aspectos éticos em representação do conhecimento: em busca do diálogo entre Antonio García Gutiérrez, Michèle Hudon e Clare Beghtol. Marília, Unesp, 2006. 123 p. Dissertação (Mestrado) - Programa de Pós-Graduação em Ciência da Informação, Faculdade de Filosofia e Ciências de Marília, Universidade Estadual Paulista, Marília, 2006. Disponível 
em: <http://www.enancib.ppgci.ufba.br/premio/UNESP_Pinho.pdf $>$. Acesso em: 24 mar. 2011.

ROWLEY, J. Informática para Bibliotecas. Brasília: Briquet de Lemos/Livros, 1994.

PEREIRA, E. C.; BUFREM, L. S. Princípios de organização e representação de conceitos em linguagens documentárias. Encontros Bibli: Revista eletrônica de Bibliotecommia e Ciência da Informação, Florianópolis, n. 20, $2^{\mathrm{o}}$ sem. 2005. Disponível em: $<$ http://www.encontrosbibli.ufsc.br/Edicao_20/2_pereira.pdf >. Acesso em: 15 set. 2007.

SAMPAIO, M. I. C. et al. PAQ - Programa de avaliação da qualidade de produtos e serviços de informação: uma experiência no SIBi/USP. Ciência da Informação, Brasília, v. 33, n. 1, jan./abril 2004. Disponível em: $<$ http://www.ibict.br/cienciadainformacao/viewarticle.php?id=93\&layout=abstract $>$. Acesso em: 03 set. 2007.

SMIT, J. W. (Coord). Análise documentária: a análise da síntese. Brasília: IBICT, 1987.

SOUZA, R. R. Sistemas de Recuperação de Informações e Mecanismos de Busca na Web: panorama atual e tendências. Perspectivas da Ciência da Informação, Belo Horizonte, v. 11, n. 2, p. 161-173, maio./ago. 2006. Disponível em: $<$ http://www.scielo.br/pdf/pci/v11n2/v11n2a02.pdf>. Acesso em: 10 dez. 2011 